\title{
AN UNUSUAL AIRGLOW WAVE EVENT OBSERVED AT CACHOEIRA PAULISTA $23^{\circ} \mathrm{S}$
}

\author{
A.F. Medeiros ${ }^{1,2}$, M.J. Taylor ${ }^{3}$, H. Takahashi ${ }^{1}$, P.P. Batista ${ }^{1}$, and D. Gobbi ${ }^{1}$ \\ (1) Instituto Nacional de Pesquisas Espaciais (INPE), Brazil \\ (2) Universidade Federal da Paraiba, Brazil \\ (3) Space Dynamics Laboratory and Physics Department, Utah State University, Logan, UT 84322, USA
}

\begin{abstract}
An all-sky CCD airglow imager has been used to obtain a wealth of data on the MLT airglow emissions from Cachoeira Paulista, Brazil $\left(22.7^{\circ} \mathrm{S}, 45.0^{\circ} \mathrm{W}\right)$. Measurements of the NIR OH, OI $(557.7 \mathrm{~nm}), \mathrm{O} 2(0,1)$ and the thermospheric OI(630.0 nm) emissions have been made since October 1998. In addition, simultaneous measurements of the airglow zenith intensities and rotational temperatures, and vertical wind structure between 80 and $100 \mathrm{~km}$ were made using a co-located multi-channel photometer and a meteor radar. On the night of July 13 , 1999 , the CCD images showed active wave events exhibiting a variety of short period wave structures. The activity started with ripple patterns over the whole sky, lasting for almost one hour. Later the patterns changed to extensive band-like structures that lasted for several hours. After local midnight a bore-like wave-front passed overhead propagating towards the North. When the front was in the zenith the image data showed an increase in both the $\mathrm{OI}(5577 \mathrm{~nm})$ and $\mathrm{O} 2(0,1)$ emissions, whilst a decrease in the $\mathrm{OH}$ intensity was observed, which is opposite to that observed by Taylor et al., (1995a). The co-located photometer revealed an exceptionally large intensity $(>40 \%)$ and temperature $(\sim 12 \%)$ perturbation throughout the night that appears to be associated with a large-scale gravity wave perturbation with significant vertical phase shift between the different emissions.
\end{abstract}

(C) 2001 COSPAR. Published by Elsevier Science Ltd. All rights reserved.

\section{INTRODUCTION}

Since internal almospheric gravity waves have been recognized as an important atmospheric phenomenon (Hines, 1960), considerable observational and theoretical research has been carried out. These efforts have established the importance of such motions as a part of the driving force of the mean circulation and thermal structure of the Mesosphere and Lower Thermosphere (MLT) region via wave energy and momentum transports (Fritts, 1989).

The airglow imaging technique provides a simple and useful method for investigating the horizontal characteristics of gravity waves and their temporal evolution at MLT heights. Most of the airglow image measurements reported in the literature relate to short-period $(<1$ hour) wave structures and they fall into two distinct categories called "bands" and "ripples". Bands are extensive, long-lasting wave patterns which exhibit horizontal wavelengths of several tens of kilometers and horizontal phase velocities up to $100 \mathrm{~m} / \mathrm{s}$ (e.g. Clairemidi et al., 1985). These patterns have been attributed to freely propagating or ducted short-period gravity waves (Walterscheid et al., 1999, Isler et al., 1997; Taylor et al., 1987). Ripples are short-lived (<45 min) small-scale wave patterns of restricted spatial extent (Peterson, 1979), and are thought to be generated in-situ by localized shear or convective-type instabilities in the total wind field (Taylor and Hapgood, 1990; Hecht et al., 1995).

This paper describes new image measurements of short period waves observed from a low-latitude site in the Southern hemisphere. In addition to the strong band and ripple activities in the night, there was new evidence of a "mesospheric bore-like" event (Taylor et al., 1995a), and a "ladder-type" event (Taylor et al., 1995b). Taylor et al. (1995a) have described what they called "a spectacular gravity wave event" during the Hawaiian Airglow (ALOHA-93) campaign by using a multi-color all-sky airglow imager, a Michelson interferometer measuring the $\mathrm{OH}$ Meinel bands and the Airborne Na Lidar. The event occurred on October 10, 1993, and appeared in the $\mathrm{OH}$ images as a linear front. Behind the front, a series of marked brightness crests and troughs were observed. The front moved with the velocity of about $76 \mathrm{~m} / \mathrm{s}$ in the $\mathrm{OH}$ emission layer $(\sim 87 \mathrm{~km}$ of altitude). This event was also 
imaged in three other airglow emission layers: sodium (hereafter $\mathrm{NaD}$ ) near $87 \mathrm{~km}$, the $\mathrm{O}_{2}(0-1)$ band (hereafter $\mathrm{O}_{2}$ ) near $94 \mathrm{~km}$, and OI $557.7 \mathrm{~nm}$ (hereafter OI) near $97 \mathrm{~km}$. Thus the event was seen at four altitudes simultaneously. While the two airglow layers in the lower heights, $\mathrm{OH}$ and $\mathrm{NaD}$, showed an enhancement of brightness extending behind the front, the two upper layers, $\mathrm{O}_{2}$ and $\mathrm{OI}$ displayed an opposite dark phase. The largest contrast in the intensity was seen in the $\mathrm{OH}$ emission. Together with these images, temperatures were obtained from the $\mathrm{OH}$ Meinel (3-1) band measurement using a ground-based interferometer. There was a sudden change in the temperature followed by an abrupt jump in intensity. This was coincident with the passage of the front in the zenith, where the interferometer was measuring. Dewan and Picard (1998) explained the event as a bore-like wave, Munassinghe et al. (1998) pointed out the possibility of dispersion of long and short period waves and Swenson et al. (1998) explained it as a large amplitude gravity wave. The event detected in Cachoeira Paulista is very similar with that observed by Taylor et al. (1995a), but it presents some different characteristics as discussed below. In the present study, this event was studied using simultaneous photometer, meteor radar, Na lidar and imager measurements.

\section{OBSERVATIONS}

Routine airglow observations have been carried out at Cachoeira Paulista (CP) using a multi-channel zenith photometer and an all-sky imaging system. This is a collaborative program between the Instituto Nacional de Pesquisas Espaciais (INPE), Brazil and the Space Dynamics Laboratory, Utah State University (Dr. M. J. Taylor). The CCD imager consists of a large area $\left(6.45 \mathrm{~cm}^{2}\right)$, high resolution, $1024 \times 1024$ back-illuminated array with a pixel depth of 14 bits. The high quantum efficiency ( $80 \%$ at visible wavelengths), low dark current $(0.5$ electrons/pixel/s), low readout noise (15 electrons $\mathrm{rms}$ ), and high linearity $(0.05 \%)$ of this device made it possible to achieve quantitative measurements of the airglow emissions. The camera uses a fast (f/4) all-sky telecentric lens system that enables high signal-to-noise (20:1) images of wave structure to be obtained with time integration of typically $15 \mathrm{~s}$ for the near-infrared $\mathrm{OH}$ emission $\left(715-930 \mathrm{~nm}\right.$ pass-band) and $90 \mathrm{~s}$ for the $\mathrm{OI}, \mathrm{O}_{2}$, and $\mathrm{OI}(630.0 \mathrm{~nm})$ emissions. The image was binned on-chip down to $512 \times 512$ resolution to enhance the signal-to-noise ratio. Table 1 lists some characteristics of interference filters used for the observations.

Table 1 -All sky imager filter characteristics and the emission peak height

\begin{tabular}{|l|l|l|l|}
\hline Filter & Filter Wavelength (nm) & Filter Bandwidth (nm) & Emission peak heights (nm) \\
\hline $\mathrm{OI}$ & 557.7 & 2.65 & $\sim 96$ \\
\hline $\mathrm{OI}$ & 630.0 & 3.30 & $\sim 275$ \\
\hline Background & 578.0 & 2.67 & $90-100$ \\
\hline $\mathrm{O}_{2}(0,1)$ & 865.5 & 12.0 & $\sim 94$ \\
\hline $\mathrm{OH}$ & $715-930^{*}$ & 215.0 & $\sim 87$ \\
\hline
\end{tabular}

* With notch at $865.5 \mathrm{~nm}$ to suppress the $\mathrm{O}_{2}(0-1)$

The wind field was observed by an SkiYmet meteor radar operated at CP. The radar typically collects 3000 to 4000 useful meteor echoes a day, making it possible to obtain hourly winds with a $3-\mathrm{km}$ interval from 82 to 100 $\mathrm{km}$. Depending on the actual number of meteors, different choice of time and height resolution can be used.

Sodium lidar observations have been carried out at São José dos Campos, $102 \mathrm{~km}$ SW of Cachoeira Paulista. The MLT sodium density profiles can be obtained for each 5 minutes with a $0.5 \mathrm{~km}$ height resolution from 80 to $110 \mathrm{~km}$. The detail of the lidar characteristics has been published elsewhere by Clemesha et al. (1995).

\section{THE NIGHT OF JULY 13, 1999}

On this night the wave activity started with various ripple patches around 19:47 LT and remained until 20:37 LT. An example of these ripples is shown in Figure 1a. From the wave analysis, it was revealed that the ripples had a horizontal wavelength of $\sim 13 \mathrm{~km}$, with a phase speed of $\sim 23 \mathrm{~m} / \mathrm{s}$ and an apparent period of $\sim 8$ minutes. They all progressed towards NW. Figure $1 \mathrm{~b}$ shows an $\mathrm{OH}$ image showing band structure extending over the whole sky and moving towards SW. Actually the bands persisted for almost the whole night propagating towards SW. The horizontal wavelength was $23.0 \pm 3.8 \mathrm{~km}$, with the horizontal phase speed of $23.9 \pm 3.9 \mathrm{~m} / \mathrm{s}$, yielding an apparent period of 16 minutes. 
After the intense ripple activity a "ladder-type" wave pattern, similar to that observed by Taylor et al., (1995b), was seen on the zenith extending perpendicular to the bands as shown in Figure 2. This pattern had a horizontal wavelength of $14.3 \pm 0.2 \mathrm{~km}$ and an apparent period of 10 minutes and moved towards SE. Ladder patterns are transient features that are thought to be due to superposition of two band-type waves propagating with slightly different angles (Taylor et al., 1995b).

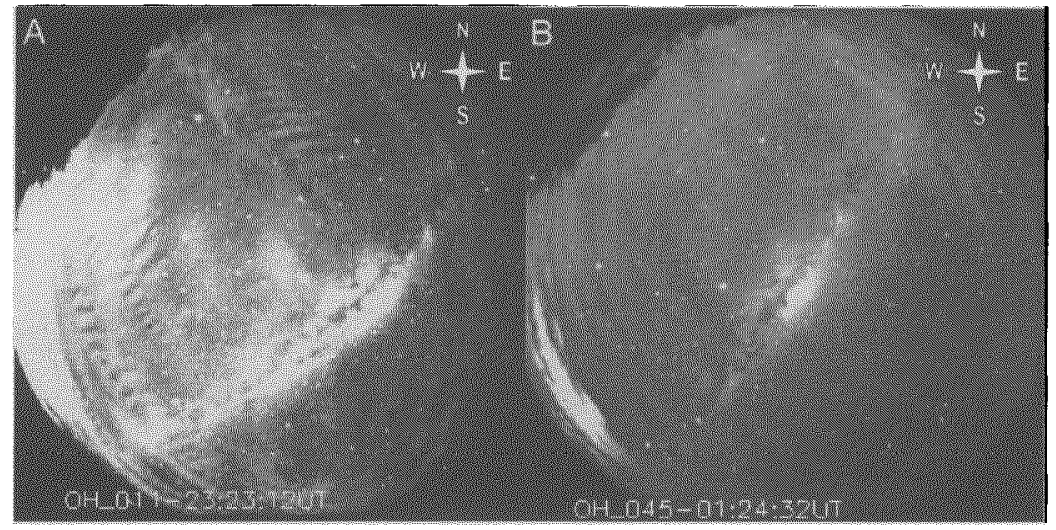

Fig. 1 - A) All sky image of the OH (715-930 nm) emission taken on July, 13 at 23:23 UT (20:23 LT). At NE and SW Ripple activity is shown. B) OH image for July, 14 at 01:24 UT (23:24 LT on July,13) showing band structure extending over the whole image and moving from NE towards the SW.

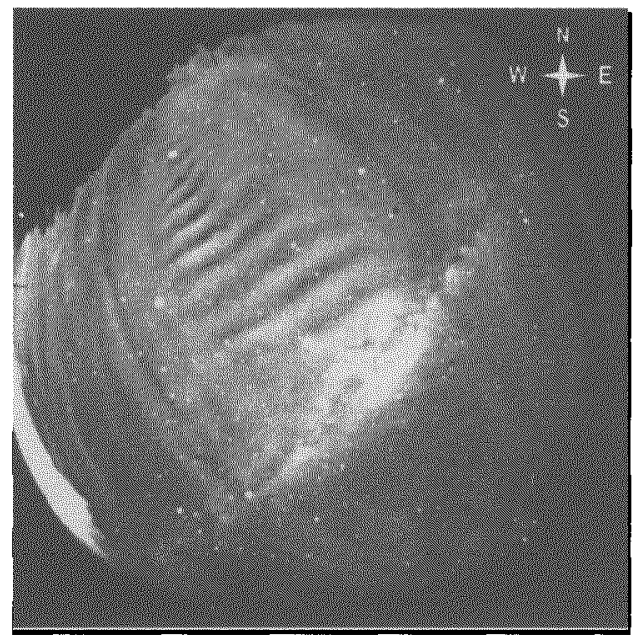

Fig. 2 - OH image for July,13 at 21:20 LT showing a "ladder-type" wave pattern. Short wavelength structures from SW to NE appear between bands extending from NW to SE.

Figure 3 shows an unwarped pair of $\mathrm{OI}$ and $\mathrm{OH}$ images projected onto a geographic grid of $512 \times 512 \mathrm{~km}$ (with pixel resolution of $1 \mathrm{~km}$ ). The images show a faint yet distinct "bore-like" front extending along the E-W direction. The bore-like event first appeared towards the south at 23:28 LT and ended by crossing the entire sky around 24:18 LT. Bores-like events are characterized by a sharp "front" and often exhibit a contrast reversal of brightness between the $\mathrm{OH}$ and $\mathrm{OI}$ cmissions. The wave train bchind the front in the frame is morc distinct for $\mathrm{OI}$ (Figure 3 left). It has a mean horizontal wavelength of $23 \mathrm{~km}$ and a horizontal phase speed of $70 \mathrm{~m} / \mathrm{s}$, with a period of $5.47 \mathrm{~min}$. These results are very similar to those observed by Taylor et al., (1995a) but the contrast reversal is in the opposite sense. 


\section{DISCUSSION}

From the OI and OH all sky images on the night of July 13,1999, we observed a series of wave-like events, starting with ripples, progressing to band structure, ladder type, growing up to the band and bore type wave front. From these waves, however, it is difficult to conclude whether these waves are traces of several gravity wave passages or the consequence of wave-wave interaction or further wind-wave interaction. For further investigation, the airglow zenith observation results are plotted in Figure 4. A description of the zenith photometer and how the temperatures are determined is given by Takahashi et al. (1974) and Takahashi et al. (1986). Nocturnal variations of the $\mathrm{OI}, \mathrm{OH}$ and $\mathrm{O}_{2}$ intensities, and the $\mathrm{OH}$ rotational temperature are shown.

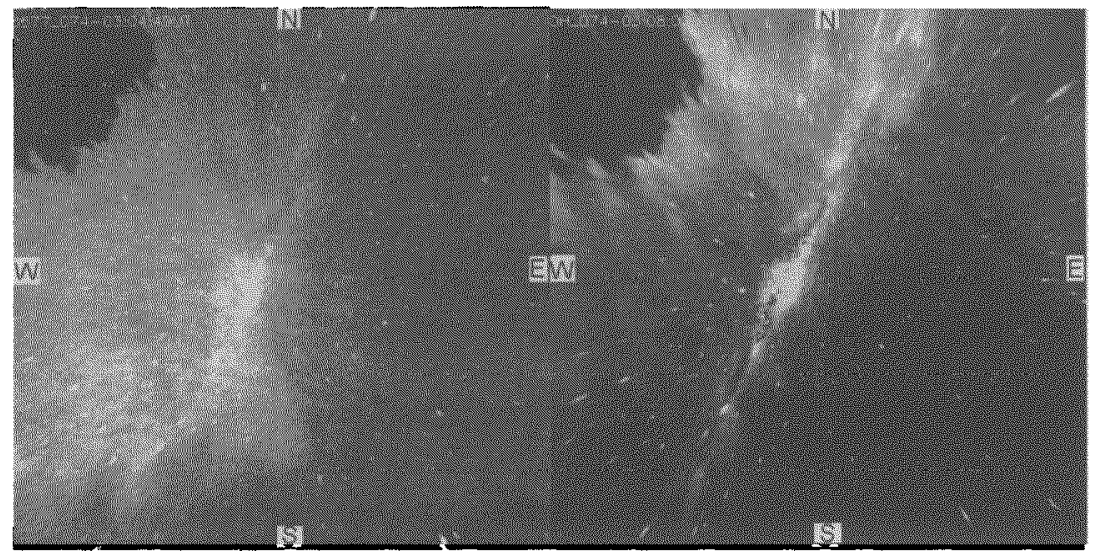

Fig. 3 - Unwarped pair of OI (left) and NIR OH (right) images projected onto a geographic grid of $512 \times 512 \mathrm{~km}$ (with pixel resolution of $1 \mathrm{~km})$. Times of the images are 03:04 UT(00:04 LT) for OI and 03:08 UT (00:08 LT) for OH
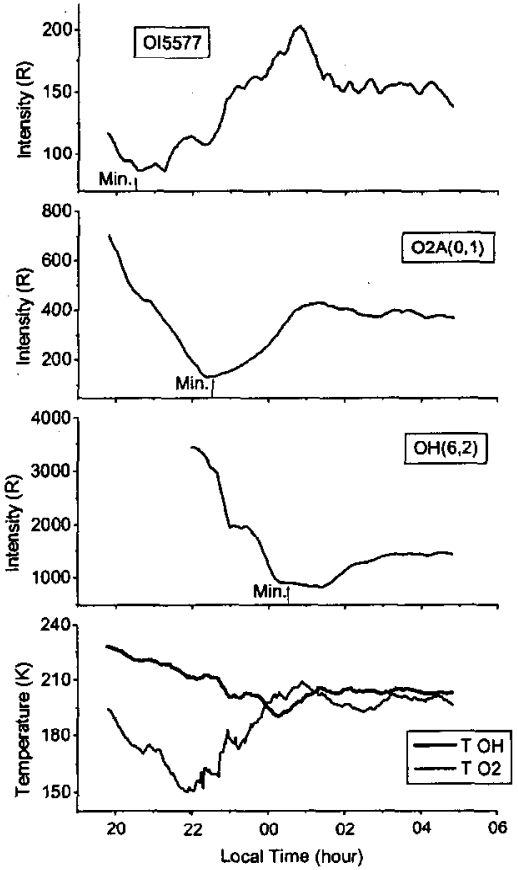

Fig 4 - Nocturnal variations of the OI, $\mathrm{O}_{2}(0,1), \mathrm{OH}(6,2)$ and temperatures with local time
Prior to the bore-like event at around 24:00 LT the intensity of $\mathrm{O}_{2}$ and $\mathrm{OH}$ decreased considerably $(\sim 30-70$ $\%)$. The decrease occurred first in OI $(97 \mathrm{~km})$ at 20:30 LT and $\mathrm{O}_{2}(94 \mathrm{~km})$ at 22:30 LT and then the OH $(87$ $\mathrm{km}$ ) at 00:30 LT, indicating that the phase of the minimum was shifting to lower heights. The $\mathrm{O}_{2}$ temperature decreased dramatically, $\sim 50 \mathrm{~K}$ during this period but with an apparent phase shift of $\sim 30 \mathrm{~min}$ leading the intensity perturbation. A similar variation but with lower amplitude of decrease was observed in the $\mathrm{OH}$ intensity and temperature perturbation about $\sim 1.5 \mathrm{hrs}$ later. These facts suggest the passage of a large-scale gravity wave, with a period much longer than $=3$ hours, and a phase propagating downwards through the emission heights. It should be noted that at around 00:30 LT when the bore-like wave front was observed in the images, the $\mathrm{OI}$ and $\mathrm{OH}$ intensities showed their maximum and minimum, respectively, and the $\mathrm{O}_{2}$ intensity was in the middle of the ascending phase. The anti-phase variation of $\mathrm{OI}$ and $\mathrm{OH}$ suggests that the vertical wavelength of this event should be longer than $10 \mathrm{~km}$ (vertical distance between the two emissions). Superposed on the large amplitude variation, short period ( $\leq 1 \mathrm{~h}$ ) oscillation patterns can be seen in the $\mathrm{OH}$ and $\mathrm{OI}$ variations before midnight. 
These correspond to the band structures observed in the image observation.

Figure 5 shows meteor radar wind profiles for 13 - 14 July, 1999. Meridional and zonal winds between 23:30 LT and 01:30 LT showed a strong shear structure. Note that the bore-like wave front passed the local zenith at around 00:20 LT.
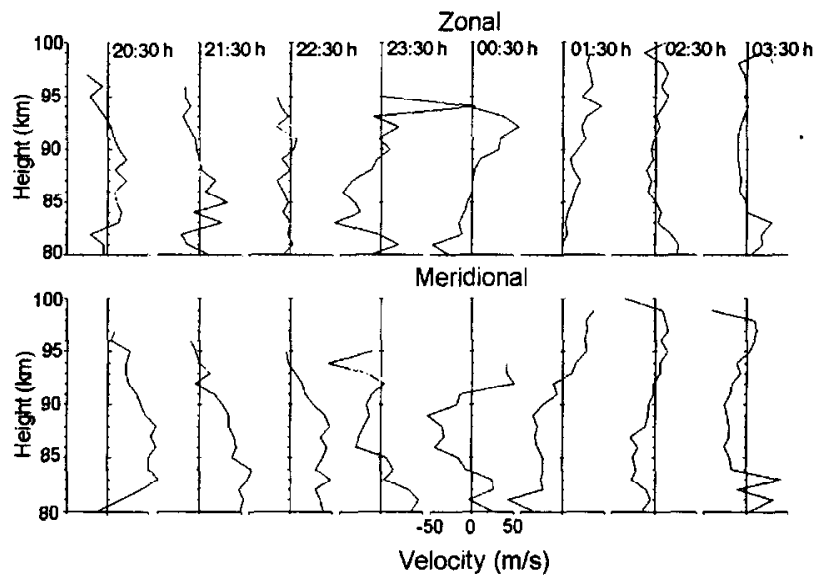

Fig 5 - Meteor radar wind profiles for every hour from 13 to 14 July, 1999.

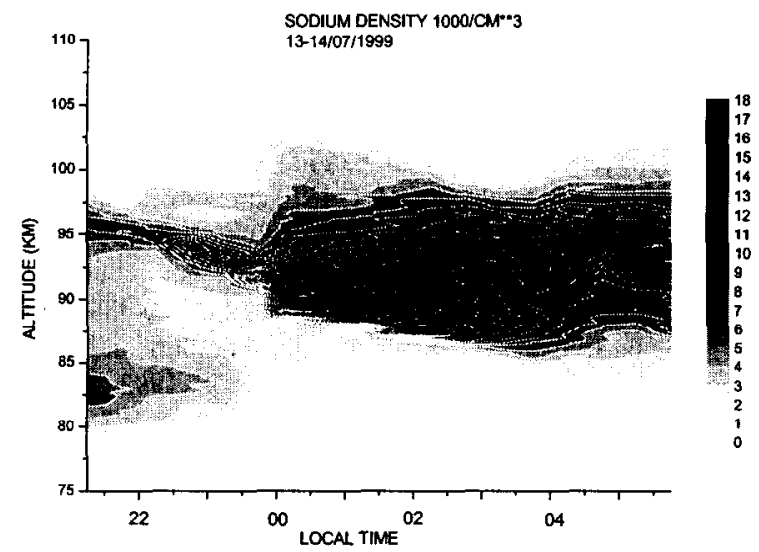

Fig. 6 - Sodium density for the night 13-14 July, 1999. Scale levels are given in $1000 \mathrm{~cm}-3$.

If we consider $87 \mathrm{~km}$ as the center of the $\mathrm{OH}$ emission layer, the total wind at 23:30 LT at this height is 44.2 $\mathrm{m} / \mathrm{s}$ towards SW, which is almost opposite to that of the $\mathrm{OH}$ front direction. This is consistent with the "bore" hypothesis presented by Dewan and Pickard, (1998). Unfortunately at the OI height ( $\sim 97 \mathrm{~km})$ wind data are not available between 22:30 LT and 24:30 LT.

Simultaneous $\mathrm{Na}$ lidar measurements (from São José dos Campos) showed a strong sporadic sodium event during the period when the bore was observed. The Figure 6 shows the sodium density map for the night of 13-14 July, 1999. Scale levels are given in units of $1000 \mathrm{~cm}^{-3}$. Note that around $21: 10 \mathrm{LT}$ the layer presented a small sporadic peak at $96 \mathrm{~km}$ and another peak at $84 \mathrm{~km}$. The top side peak grew as it dropped to $92 \mathrm{~km}$, at the same time, the lower peak disappeared at 23:45 LT. At around this time the layer shape changed, with the sodium almost disappearing below $85 \mathrm{~km}$, and the sporadic peak moved further downward and the density increased at the topside of the layer. These facts suggest that there was a strong gravity wave event with a period of more than 4 hours and its phase propagating downward with a velocity of about $1.5 \mathrm{~km} / \mathrm{h}$, which is consistent with the photometer results. 


\section{SUMMARY}

We have presented preliminary results of the airglow $\mathrm{OI}, \mathrm{OH}$ and $\mathrm{O}_{2}$ image observation carried out on the night of 13 July 1999. The images revealed 4 different types of events during the night, i. e., ripples, bands, ladders and bore-like. During the zenith $\mathrm{OI}$ intensity increasing phase and the zenith $\mathrm{OH}$ intensity decreasing phase, ripple and band structures appeared. The bore-like front was observed when the $\mathrm{OI}$ and $\mathrm{OH}$ reached their maximum and minimum intensities, respectively. The $\mathrm{O}_{2}$ temperature decreased dramatically, $\sim 40-50 \mathrm{~K}$ during this period, but with the temperature leading by $\sim 30$ minutes the intensity perturbation. Meteor radar wind profiles $(80-100 \mathrm{~km})$ showed meridional and zonal wind shears during the passage of the bore. The NaD lidar measurements showed a strong sporadic sodium event shifting downwards during the period when the bore-like event was observed. All of these data suggest a very strong large-scale wave progressing downwards through the MLT emission region on this night.

\section{ACKNOWLEDGMENTS}

We gratefully acknowledge the financial support of the Coordenação de Aperfeiçoamento de Pessoal de Nivel Superior - CAPES and the Conselho Nacional de Desenvolvimento Científico e Tecnológico - CNPq. The USU camera and operations were supported by NSF grant No ATM-9525815.

\section{REFERENCES}

Clairemidi J., M. Herse and G. Moreels, Bi-dimensional observation of waves near the mesopause at auroral latitudes, Planet. Space Sci., 33, 1013-1022, 1985.

Clemesha B. R., Sporadic neutral metal layers in the mesophere and lower thermosphere, Journal of Atmopheric and terrestrial Physics, 57, 725-736, 1995.

Dewan E. M. and R. H. Picard, Mesopheric bores, J. Geophys. Res., 103, 6295-6306, 1998.

Fritts D. C., A review of gravity wave saturation processes, effects, and variability in the middle atmosphere, Pageoph, 130, 3343-371, 1989.

Hecht J. H., S. R. R. Howat, R. L. Waltershceid and J. R. Isler, Observations of spectra of intensity flutuations of the OH Meinel nightglow during ALOHA-93, Geophys. Res. Lett., 22:(20), 28373-2876, 1995.

Hines C. O., Internal tmospheric gravity waves at ionospheric heights, Can. J. Phys, 38, 1441-1481, 1960.

Munasinghe G. H., H. Hur, T. Y. Huang, A. Bhattachyya and T. F. Tuan, Application of the dispersion formula to long-and short-period gravity waves: Comparisons with ALOHA-93 data and analytical model, J. Geophys. Res., 103, 6467-6481, 1998.

Peterson A. W., Airglow events visible to the naked eye, Appl. Optics, 22, 3390-3393, 1979.

Swenson G., J. Qian, J. M. C. Plane, P. J. Espy, M. J. Taylor, N. Turnbull and R. P. Lowe, Dynamical and chemical aspects of the mesopherics $\mathrm{Na}$ "wall"event on October 9, 1993 during the Aiborne Lidar and Observations of Hawaiian Airglow (ALOHA) campaign, J. Geophys. Res., 103, 6361-6380, 1998.

Takahashi H., Y. Sahay and P. P. Batista, Airglow O2 $\left.{ }^{1} \Sigma\right)$ atmospheric band at $8645 \AA$ and the rotational temperature observed at $23^{\circ}$ S, Planet. Space Sci., 34, 301-306, 1986.

Takahashi H., B. R. Clemesha and Y. Sahay, Nightglow OH $(8,3)$ band intensities and rotational temperature at 23 degreess, Planetary and Space Science, 22:(9), 1323-1329, 1974.

Taylor M. J. and M. A. Hapgood, On the origin of ripple-type wave structure in the nightglow emission, Planet. Space Sci., 38, 1421-1430, 1990.

Taylor M. J., D. C. Fritts and J. R. Isler, Determination of horizontal and vertical structure of an unusual pattern of short period gravity waves imaged during ALOHA-93, Geophys. Res. Lett., 22, 2837-2840, $1995 \mathrm{~b}$.

Taylor M. J., D. N. Turnbull and R. P. Lowe, Spectrometric and imaging measurements of a spectacular gravity wave event observed during the ALOHA-93 campaign, Geophys. Res. Lett., 22, 2849-2852, 1995 a.

Taylor M. J., M. A. Hapgood and P. Rothwell, Observations of gravity wave propagation in the OI (557.7 nm), Na $(589.2 \mathrm{~nm})$ and the near infrared $\mathrm{OH}$ nightglow emissions, Planet. Space Sci, 35, 413-427, 1987.

Waterscheid J. H., J. H. Hecht, R. A. Vicent, I. M. Reid, J. Woithe and M. P. Hickey, Analysis and interpretation of airglow and radar observations of quasi-monochromatic gravity waves in the upper mesosphere and lower thermosphere over Adelaide, Australia $\left(35^{\circ} \mathrm{S}, 138^{\circ} \mathrm{E}\right)$, Journal of Atmospheric and Solar-Terrestrial Physics, 61, 461-478, 1999. 